\title{
Revisiting incremental product innovations in the food-manufacturing industry: an empirical study on the effect of intellectual property rights
}

\author{
Tohru Yoshioka-Kobayashi ${ }^{1}$, Tomofumi Miyanoshita ${ }^{2}$ and Daisuke Kanama ${ }^{3^{*}}$ (1)
}

\author{
*Correspondence: \\ kanama@staff.kanazawa-u.ac.jp \\ ${ }^{3}$ School of Economics, Kanazawa \\ University, Kakuma-machi, \\ Kanazawa, Japan \\ Full list of author information \\ is available at the end of the \\ article
}

\begin{abstract}
The highly competitive and mature food industry has long been process innovationoriented while largely neglecting product/technological innovation. However, recent innovation debates have raised two issues. First, imitations of product innovations likely underestimate the value of innovation in this industry; second, exaggerations of new product development neglect incremental product innovations, which facilitate branding. Using intellectual property rights data as indicators of exclusive innovation outcomes, this study empirically examined these issues. The distinction of consumer communication channel-related designs from other industrial designs utilizing the advantage of the simple structure of foods has realized highly fitted proxies of distinctive innovation activities. Investigating the firm performance of 192 Japanese food manufactures between 2009 and 2013 revealed the dominance of incremental innovations in product packaging over other exclusive innovations. This study provides practical insights regarding innovations for the industry and evidence of the effectiveness of consumer communication-related designs of patents, especially as novel innovation proxies.
\end{abstract}

Keywords: Incremental product innovation, Food manufacturing industry, Intellectual property right, Innovations in the static industry

\section{Introduction}

It has long been a big argument as to what types of innovations contribute to the enhancement of the competitiveness of firms. According to Prajogo (2016), product innovations are effective in the changing environment but are ineffective in the competitive market. Rather, process innovations show superiority in a fiercely competitive industry. Another perspective of innovation research emphasizes technological innovation as one of the most inimitable innovations (Xin et al. 2010). Indeed, many product innovations, including new products and new features of products (such as designs or promotions), are targets of imitations (Bigliardi and Galati 2013), while the majority of process innovations are hardly imitated due to secrecy of the manufacturing processes 
or its dependence on social network-based supply chains. In particular, in a competitive and matured market, innovative firms encounter many copycats. As mentioned below, past literature except a few reports has not investigated the economic impact of incremental product innovations (IPIs) in the food-manufacturing industry or even its potential. As a fiercely competitive industry, imitations may hinder effective analysis. This study attempts to overcome this limitation by focusing on three different intellectual properties rights (IPRs) as proxies of different types of hard-to-imitate innovations. Prior scholarly works validated these proxies by examining their correlations with various firm performance indicators. Following these works, this study tests the impact of different types of innovation on firm financial performance.

Innovation trends in the food-manufacturing industry, one of the most competitive and matured businesses, clearly recollect this theoretical question. Previous studies have noted that firms in the food-manufacturing industry do not substantially facilitate product and technological innovation activities, compared with other manufacturing industries (Beckeman and Skjöldebrand 2007; Christensen et al. 1996; Hullova et al. 2019). This is evidenced by the low ratio of research and development (R\&D) intensity to sales (Beckeman and Skjöldebrand 2007; Garcia Martinez and Briz 2000; Trott and Simms 2017) and by small amount of patent applications (Christensen et al. 1996; Dernis et al. 2015; Garcia Martinez and Briz 2000). Rather, this industry has been process innovation-oriented (Archibugi et al. 1991; Batterink et al. 2006; Triguero et al. 2013). Reality indicates that product innovations are endogenously inferior to process innovations in the food manufacturing industry.

Still, we need further validation for judging the values of product innovations in this industry. Product innovations contain multiple aspects other than new product development. In particular, this study focuses IPI, which implements small changes in a product's characteristics, design, quality, functions, or components to satisfy the needs of the consumers (Bhaskaran 2006). In fact, some empirical studies have referred to such innovation as a marketing innovation and revealed the positive effects of narrowly defined product innovations and innovation performance of firms (Gunday et al. 2011). However, without any exclusivity, IPIs will soon lose competitiveness. Therefore, firms have tried to protect their products by registering IPRs preventing counterfeits (Japan Patent Office, 2011, 2017). For example, as Silayoi and Speece (2007) note, packaging affects consumers' product selection and willingness to pay; once a package with a new design is recognized by consumers, it is expected that continuously utilizing it will gradually lead to sales and profits. Naturally, firms will thus continue to protect the design patent, expecting the long-term preservation of design patents reflects building the brand and preventing competitor's imitation.

On the other hand, if the number of IPRs is too high, it will be difficult to maintain consistency with the product development strategy inside the firm. Fleming and Sorenson (2001) proved using patent data that as the number of element technologies increases, the possibility of interaction between technologies and products will increase, and as a result, it becomes difficult to combine them. This is reflected as a firm's marginal costs. Furthermore, from the viewpoint of IP management, the maintenance of IPRs and monitoring for counterfeit goods in the market are the primary tasks. In other words, the better the design or technology, the higher the need for posterior costs. These 
arguments show that while IPI activities make a positive contribution to firm performance, there is a limit due to the increasing organizational and managerial costs. Most of IPRs such as patent and design patent can be retained for 20 years after registration, and it should be examined how much this retention increases the difficulty of imitating the target product and contributes to sales and profits.

This study revisits the value of product innovations in the food-manufacturing industry by differentiating new product development and IPIs and by focusing on innovations protected by IPRs. In specific, we examined how new product development and IPI affect the firm performance (i.e., sales and profits). As mentioned in the next section, IPRs have been used as a representative proxy of product and process innovation activities in numerous studies. But only a few studies have evaluated the impact of IPRs on firm performance in the food industry. In this study, we adopted a new approach in which patents, design patents, and trademarks are included as proxy variables for each innovation activity, while using the method used in innovation studies for other industries. This methodological setting realizes the control of endogeneity between the probability of imitations of certain types of innovations and the returns from them. In doing so, there are two academic contributions of this study. First, it quantitatively indicates the extent to which the effect of IPI, which has been difficult to quantitatively verify to date, contributes to the improvement in firm performance. Second, it proposes a new quantitative method to demonstrate firm performance based on IPRs, which has been challenging to analyze for the reasons noted above.

In the next section, we describe the relation between strategic choice of innovations and their economic returns and between IPRs and types of innovations. In Sect. 3, we state the methodology of our empirical analyses and show their results in Sect. 4. In the subsequent section, we discuss interpretations of our econometrical achievements and logical deductions. Finally, managerial implications and limitations are provided.

\section{Literature review and hypothesis construction}

\subsection{Types of effective innovations in the food-manufacturing industry}

Although the food-manufacturing industry shows lower R\&D intensity, its business environment has changed immensely in the past two decades (Aguilera 2006, 2008). Stringent and diversified consumer demands request consumer-needs-led R\&D (Aguilera 2006). Several technological changes impact on the product, food supply chain, and business model itself (Omta and Folstar 2005). As a result, firms have stepped up their innovation activities, whereas innovation management has begun to have a considerable influence on the firms' competitiveness (Capitanio et al. Pascucci 2010; Grunert et al. 2005; Rama and von Tunzelmann 2008).

Product innovations in this industry put a high priority on IPIs as well as on new product developments (Menrad 2004). In particular, branding through minor changes in functions, packages, or size of the product, or extensions of product line-ups, constitutes an important part of IPIs. In contrast to the introduction of new products, branding activities are economically reasonable in this competitive and consumer-oriented market. According to Narayan (2012), a brand is an important asset for generating revenue. A strong brand ensures the trustworthiness of a product and provides its supplier with a significant return (Keller and Lehmann 2006). In addition, branding maintains 
competitive superiority in the long term (Keller 2003), generates premium pricing (Ailawadi et al. 2003; Huang and Sarigöllü 2014), improves the cash flow of the owner, and reduces overall costs (Doyle 2000). Several studies revealed that a brand plays an important role in food or beverage firm and firms increasingly allocate their resources into branding activities (Fernández-Barcala and González-Díaz 2006; Kathuria and Gill 2013; Knowles 2003).

Introduction of new package design is a key measure of IPIs to attract consumers even when the product itself is not new (Schoormans and Robben, 1997). Silayoi and Speece (2007) highlighted the positive influence of package designs on consumers' appetite for buying and their willingness to pay. In addition, once the package is unique, it works as a signal of the brand (Prendergast and Pitt 1996; Young 2004). In other words, original package designs not only raise short-term returns by attracting consumers but also enhance long-term profits by maintaining product brands. Conversely, several arguments have mentioned the negative aspect of new package introduction as established packages maintain loyal customers. For example, Garber et al. (2000) indicate that a product with loyal customers tends to lose them when the package is changed, whereas the product without such customers gains additional willingness to pay when the package is redesigned. Firms confront the dilemma of whether or not they should change package designs.

Selections of certain types of innovations are heavily influenced by their innovation capabilities. Firm size affects the intensities of certain types of innovations. Large firms prefer new product developments and medium firms like to conduct process innovations (Traill and Meulenberg 2001). IPIs are a useful option for small and medium entities, which constitute the majority in the food industry and have limited resources.

\subsection{Innovations and intellectual property rights}

IPRs (patents, trademark registrations, and design patents) grant innovators certain exclusivity to the implementation of these innovations. Of course, their exclusivity is not absolute. Some protected innovations are evaded by design around, and some are intentionally infringed by malicious followers. Despite their imperfection, they offer at least a first-mover advantage and divert competitors, resulting in some financial returns.

In the management study, IPRs are regarded as an indicator of innovations (e.g., in the food industry, Grashuis 2019; Grashuis and Dary 2017). Patents have been used as a representative proxy of product and process innovation activities in numerous studies. For example, Scherer (1965) concluded that there is a positive correlation between the number of patent registrations and sales growth by analyzing 365 American firms listed in Fortune 500. Comanor and Scherer (1969) revealed a positive relation between the number of patents and the sales of new products, with a time lag of approximately 3 years. Similar results were obtained by Ernst (2001). His paper identified a strong positive correlation between the number of applications of patents and sales, with a time lag of 2-3 years. Alfranca et al. (2002) reveal that global F\&B firms show a stable pattern of technological accumulation in which "success breeds success".

In recent years, emerging studies have been using trademark applications as an indicator of product innovation output. Mendonça et al. (2004) argued that the number of trademark applications reflects new product developments, since firms tend to apply for 
trademark rights immediately before the launch of the new product, whereas patents are applied for during the development R\&D phase. Although trademark applications represent new product developments rather than product innovations in the narrow definition, only a few empirical studies have discovered a correlation between trademark applications and firm performance. For instance, Sandner and Block (2011) confirmed that trademark applications help increase the market value of firms. Similarly, Greenhalgh and Rogers (2007) noted that applications for trademark rights help increase the market value of firms in many (but not all) industries. In addition, Greenhalgh et al. (2011) compared a sample of firms that own and do not own trademark rights and revealed that the sales growth ratio was higher among the firms that owned trademark rights than those that did not own such rights.

In contrast to patents and trademark rights, design patents, which protect novel shapes of products, contain certain complexities in their relationship with innovation activities. Indeed, design patents are the primary measure to protect aesthetic innovations (Filitz et al. 2015) and design-award winning products (Yoshioka-Kobayashi et al. 2018). However, they inherently cover various innovation outputs such as new product shapes, package designs, and advertisement equipment as well as three-dimensional shapes of novel tools or machines for production. In other words, they can protect various innovations such as product innovations, IPIs, and a part of process innovations. For example, approximately half of the applicants in Japan aim to protect technological features and aesthetical shapes (Japan Patent Office 2007). Due to such complexities, design patents have generally been left out of econometric analyses. More specifically, several non-reviewed papers have reported contradicting results. Aoki and Odagiri (2008) discovered a positive correlation in Japanese publicly listed firms between Tobin's Q ratio and design patents stocks. Conversely, Nakamura and Matsumoto (2009) investigated Japanese publicly listed firms and confirmed a non-significant correlation between Tobin's $Q$ ratio and the number of applications for design patents per total assets except in the food-manufacturing industry in which they found a positive correlations. Interestingly, Bascavusoglu-Moreau and Tether (2011) examined UK manufacturing firms and found a positive correlation before 2002 and a negative correlation in 2007 between the sales per employees and firms having at least one registered design in the UK. This inconsistency implies the complexity of design patents.

The food-manufacturing industry, however, is one exception of this complexity. As discussed above, technological innovations in this industry are limited, and the shape of a product is not always a source of competition. The primary competence of the industry includes brands, tastes, marketing, and package designs. Thus, major subject matters of design patents in this industry are package designs, and manufacturing or delivery equipment. We can measure IPIs and a part of process innovations using design patents.

\subsection{Hypotheses}

Our theoretical argument leads to two outcomes of certain types of innovations. One is the short-term return of attraction of consumers, which is delivered from the introduction of new product or packages. The other is the long-term benefits arising from branding and inimitable innovative products. IPRs are advantageous in testing 


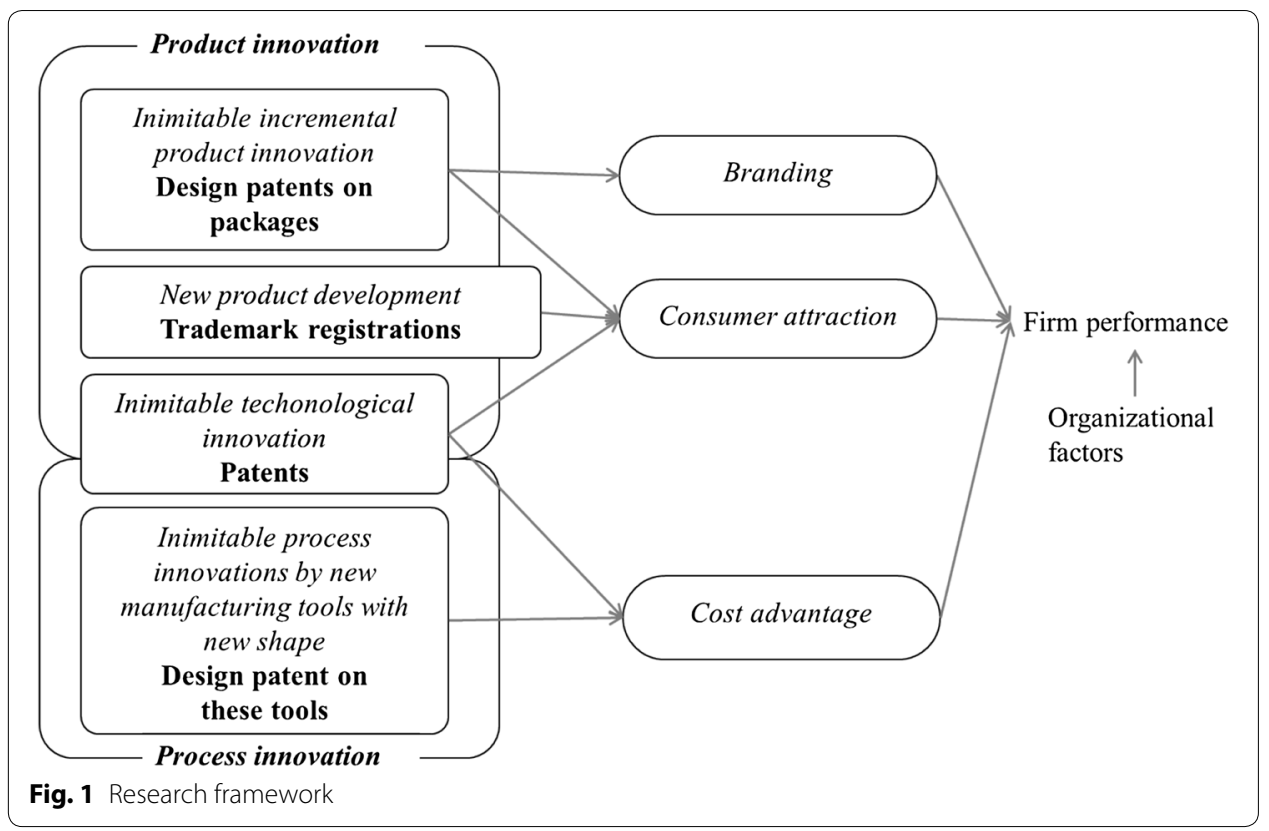

these two different returns. New registrations-in other words, flows of IPRs-represent new introductions of innovations while their stocks indicate accumulated innovations.

IPIs have both aspects. In particular, regarding package designs, their new introductions may increase sales or revenues from their implemented products and their stocks may bring long-term profits. Considering the characteristics of this industry, these innovations show relatively higher impact than other types of innovations, at least higher than technological innovations. If not, we cannot explain the lower R\&D intensity in this industry. As a consequence, this study generates and verifies the following hypotheses.

Hypothesis 1: A new introduction of hard-to-imitate package designs increases the firm performance, particularly sales growth.

Hypothesis 2: Accumulated hard-to-imitate package designs increase the firm performance, particularly profits.

Hypothesis 3: Hard-to-imitate package designs have a higher impact on the firm performance than hard-to-imitate technological innovations.

Our theoretical framework is shown in Fig. 1. We analyze product innovations in depth by focusing inimitable incremental innovations and inimitable technological innovations. The former is likely to attract consumers and establish brands. Technological innovations include certain types of process innovations, but we do not distinct two innovations because they are not our primary interest. We also considered other process innovations, which are measurable by design patents. These process innovations also improve firm performance through cost reductions. New product developments, a major element of product innovation, also contribute to the fruit. This study captures such innovations with trademark registrations, which protrude from the introduction of products new to the market. 


\section{Methodology}

\subsection{Dataset}

Our research framework confronts an important limitation: availability of sufficient design patents with detailed classifications of subject matters. For example, European countries have an efficient industrial protection system (Filitz et al. 2015). However, its registrations contain only sketchy classifications. Distinctions of design patent into two different innovations require a manual procedure. In contrast, industrial design protection systems in Japan, Korea, and the United States provide a precise classification of registered designs. Moreover, granted designs in these nations are certificated its novelty.

A further challenge of our analysis is the market structure. Some food and beverage industries are under a strong influence of dominant manufacturers. In the United States, several giant multinationals, such as Mars, Mondelez, and Kellogs, actively compete in the market. We require a more complicated research framework to analyze the industry in the country. Antithetically, Japanese and Korean industries consist of several leading manufacturers (Meiji, Nippon Ham, and Ajinomoto in Japan; CJ, Nongshim, and Samyung in Korea) and numerous small- and medium-sized entities (SMEs).

Therefore, this study analyzed 192 Japanese food and beverage firms to verify the model. More specifically, the sample consisted of 103 publicly listed firms on the Tokyo Exchange and 93 unlisted firms obtained from the 2008 to 2014 Japanese Influential Non-Listed Firm Annual Handbook (Kigyo Shikiho Mijoujouban). We selected the firms that produced products for end-customers and eliminated those that specialized in B2B services such as original equipment manufacturers and foodstuff/food material manufacturers.

The period from 2009 to 2013 was chosen as the analysis period to eliminate the effects of the economic downturn precipitated by the Lehman Brothers bankruptcy. To investigate the number of possessions (stocks), we acquired patent and design patents' data beginning from $1990 .{ }^{1}$ Then, we tracked the transition of the applicant name for each firm in the past and the principal subsidiaries that applied for IPR, based on the applicant name disambiguation database, which is provided by the National Institute of Science and Technology Policy of Japan. The patent and design patents' data were acquired from a commercial patent and design patents' database. To correct some defects, we completed the dataset using the official design patents' database provided by the Japan Patent Office. Finally, trademark data were acquired from the official trademark rights database, whereas financial data were obtained from the Nikkei NEEDS commercial database and the Kigyo Shikiho Mijoujouban (see above).

\subsection{Variables}

\subsubsection{Dependent variables}

As our assumption is that innovation activities generate additional sales and profits, we adopt sales and operating profits as firm performance indicators. The dependent variables used in this study included (1) the logarithmic value of operating profits (Hsu et al. 2013); (2) annual growth rate of sales (\%) (Scherer 1965); and (3) annual growth

\footnotetext{
${ }^{1}$ In Japan, patent have a duration of 20 years from the time of application and design rights have a duration of 20 years from the time of registration. Therefore, we acquired data filed after 1990.
} 
of operating profits. For operating profits, we adjusted each firm's difference in a given accounting period. More specifically, if the operating profits, $r(t)$, of year $t$ closed in month $n$, then the adjusted sales, $R(t)$, were calculated as follows:

$$
R(t)=r(t) \times n / 12+r(t+1) \times(12-n) / 12 .
$$

Seasonal changes were not reflected in the results of the calculation. Also, we indicated the value obtained as defective in cases where deriving an accurate value was impossible due to changes in the accounting period.

\subsubsection{Independent variables}

Among the independent variables, stock and flow (the number of applications or new registrations) corresponding to both patent and design patents were used. In this case, "stock" is defined as the total number of rights that were confirmed as effective at a certain point in time at year $t$, whereas "flow" is the number of cases accumulated from $t$ -2 years to $t$ year (3 years). We chose 3 years as the duration based on Ernst's (2001) claim that firm performance is reflected several years after patent application.

The number of applications in year $t$ was counted for both trademark and design patents, based on the following reasons. First, the interval between the application and the registration for trademark rights and design patents is less than 1 year. Second, regarding trademarks, their applications well represent new product or service introductions (Greenhalgh and Rogers 2007; Sandner and Block 2011; Schautschick and Greenhalgh 2016), focused on applications for trademark rights. Third, when examining the data from the perspective of intellectual property, the exclusive effect of owning trademark rights is limited to restricting competitors from using a given name and trademark. For these reasons, we positioned trademark rights as a proxy for the development of a new product line.

As discussed above, design patents in Japan are used to protect both the technological configuration and the outer shape of a product, as a communication channel to consumers. These purposes differ in that the former pertains to the protection of technological innovation, whereas the latter corresponds to the protection of IPI. Moreover, design protections on package designs are often used for the purpose of maintaining the product brand using a specific package design over the long term. In fact, $41 \%$ of the Japanese manufacturers that conduct R\&D stated in the questionnaire survey that package design protections are primarily for the brand creation of products or services. Meanwhile, only $23 \%$ the respondents based their reason on the protection of other types of industrial designs (Japan Patent Office 2010a).

To categorize design patents, each design patent is assigned by an examiner of the Japan Classification for Industrial Design (JCID) (Table 1). Based on this process, we selected several classifications, which is apparently related to the following three purposes: (1) communication channel-related designs such as packages, display instruments for shops, and advertisement equipment (package-related designs); (2) product shape designs, including the shapes of food products or tableware (food shapes and tableware); and (3) process innovation-related designs such as shapes of tools or machines for production or transportation (manufacturing equipment). The difference between the first (packages) and second (tableware) purposes is their role; that is, the former provides 
Table 1 Descriptions regarding the classifications of design categories

\begin{tabular}{llll}
\hline Defined category & JCID & Description of the classification & No. of designs \\
\hline Packages and related aspects & B3 & Additional clothing accessories and personal goods & 13 \\
& C2 & Interior decorations & 14 \\
& C66 & Food dispenser & 98 \\
& F3 & Papers products for office work, printed matters, and & 10 \\
& F4 & related materials & Wrapping paper, containers, and related materials \\
& F5 & Ad instruments, indicators, goods, and display instru- & 3253 \\
& J5 & Automatic vending and service machines & 24 \\
Food shapes and tableware & A1 & Processed foods and favorite goods & 47 \\
& C5 & Tableware or cooking vessels & 168 \\
Manufacturing equipment & C62 & Cooking auxiliary equipment & 150 \\
& G1 & Machine appliances for conveyance, lifts, and freight & 29 \\
& G2 & Vehicles & 6 \\
& K4 & Food processing machines and related equipment & 17 \\
K6 & Chemical machinery and instruments & 23
\end{tabular}

communication to consumers at the time of purchasing, whereas the latter often works as a communication channel at the time of consumption. Since JCIDs are assigned by professional examiners in accordance with the detailed guidebook, its reliability is quite high.

\subsubsection{Control variables}

The control variables are the logarithmic value of the number of employees and asset intensity, which is the volume of total assets divided by the number of employees (both variables are only for listed firms). The annual amount of sales in the previous year is also treated as a control variable. It is important to note that some dependent variables that we focused on included differences, compared to those in the previous year. To avoid multicollinearity in the regression estimation, we excluded the data regarding the amount of $R \& D$ and advertising expenditure, since such data exhibit a high correlation coefficient (greater than 0.8 ) with the number of employees.

\subsection{Descriptive statistics}

The descriptive statistics of the variables is presented in Table 2.

\subsection{Analysis model}

We estimated the variables using the multiple regression methods. Since no appropriate variable was available to capture the differences in the particularities (e.g., business model) among the firms, we used a fixed effects model for estimation to control for a firm's ability. We also used the estimations as panel data for each firm over a 5-year term. Although both the F- and Hausman tests confirmed that the fixed effects model is the most appropriate for sales, operating income, and year-over-year growth rate of sales, we used a pool model with the F-test for year-over-year growth in operating income. 
Table 2 Fundamental statistics of the variables

\begin{tabular}{llllll}
\hline & & Min & Max & Avr. & Std. Dev. \\
\hline 1$)$ & Operating profits & -2188 & 153,022 & 5778 & 16,288 \\
2) & Annual growth rate of sales (\%) & -33.546 & 50.198 & 0.388 & 6.099 \\
$3)$ & Annual growth of operating profits & $-17,542$ & 23,177 & 175 & 2077 \\
$4)$ & Stock of patents & 0 & 1056 & 45.262 & 123.6 \\
5) & Flow of patens (previous 3 years) & 0 & 497 & 18.137 & 56.246 \\
6) & Flow of trademark registrations & 0 & 362 & 17.364 & 42.16 \\
7) & Stock of design patents (packages and related) & 0 & 251 & 6.176 & 24.338 \\
$8)$ & Stock of design patents (food shapes and tableware) & 0 & 34 & 0.557 & 2.401 \\
$9)$ & Stock of design patents (manufacturing equipment) & 0 & 7 & 0.226 & 0.916 \\
$10)$ & Flow of design patents (packages and related) & 0 & 41 & 0.683 & 3.399 \\
$11)$ & Flow of design patents (food shapes and tableware) & 0 & 20 & 0.071 & 0.778 \\
$12)$ & Flow of design patents (manufacturing equipment) & 0 & 6 & 0.025 & 0.252 \\
$13)$ & Log (Number of employees) & 3.359 & 10.627 & 6.801 & 1.427 \\
$14)$ & Asset intensity & 5.013 & 166.798 & 51.74 & 27.985 \\
$15)$ & Listed dummy & 0 & 1 & 0.469 & 0.499 \\
\hline
\end{tabular}

We first estimated the effects of IPRs' stocks on sales and operating profits. However, we did not adopt any flow variables since they have simultaneity bias with firm performance. In short, firms may apply more IPR during their prosperous periods. The second step was to identify the mechanisms of contribution to firm performance. Several innovations, such as new product development, may have short-term effects, whereas branding activities can have long-lasting effects. To distinguish these two different mechanisms, we estimated the effects of their stocks and flows on growths of sales and operating profits. Exceptionally, we apply the number of trademark applications as a proxy of new product development activities. We do not use any stock variable since the accumulation of trademark registrations is theoretically considered meaningless in the innovation context.

These multiple regression results can be interpreted as follows (Table 3). If a stock has a significant effect on sales or profits, and no significant effects on growth are observed in the stock and its flow (Case 1), then it indicates that IPR generates stable high sales or revenue, but they do not bring any growth. In this regard, we can assume that branding helps realize customer loyalty or premium pricing (Ailawadi et al. 2003; Huang and Sarigöllü 2014). In addition, if a stock has a significant effect on both sales/profits and its growth, but its flow has no significant effect (Case 2), then the source of sustainable competitive advantage (protected by IPR) expands its demand. Finally, if significant positive correlations are observed between a stock and sales/profits, and between a flow and its growth, but there are no significant relations between a stock and its growth, then we can interpret this as two distinguished phenomena. On the one hand, it may simply indicate simultaneity and the growth of the firm's performance probably induced further IPR applications. On the other hand, the results may display the short-term impact of innovation activities.

Still, there is a possibility of including some unobserved variable biases. Typically, knowhow is a key unobserved variable. As debated above, process innovations are likely kept secret. However, in reality, the proportion of knowhow in the food-manufacturing 
Table 3 Possible results of the multiple regressions and their interpretations

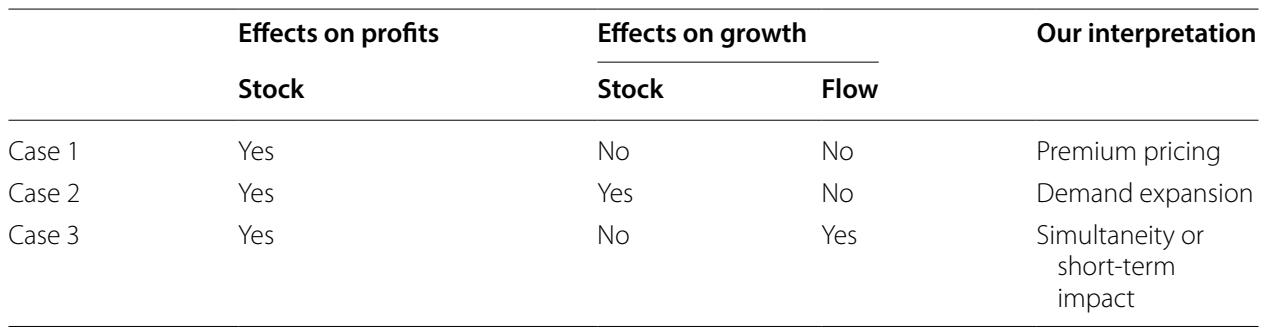

industry is not significantly larger than in other industries. A recent report of the questionnaire survey for 1268 Japanese firms revealed that a ratio of the number of knowhow to the quantity of knowhow and patents is $24.3 \%$, slightly higher than the cross-industry average (22.9\%), while the chemical industry marks at 32.9\% (Yamauchi et al. 2012). In line with past literature, we do not control for any effects from knowhow due the measurement difficulty. Another unobserved determinant of firm performance is innovation without any IPR protections. We can assume that such innovations are not protected because of their limited value, at least from the firm's viewpoint. Past research measured these activities through questionnaire surveys, which is ineffective in obtaining longitudinal data. In the food industry, organizational resources have a strong influence on innovation performance (Avermaete et al. 2004; Capitanio et al. 2010; Traill and Meulenberg 2001). This study placed priority on controlling for these firm-fixed resource effects over this unobserved variable.

\section{Results}

\subsection{IPR stocks}

The estimation results of operating profits indicate that the stock of packages and related design patents significantly and positively correlated with the dependent variable. Moreover, the coefficient shows that each additional package and related design patent generates 88 million Japanese yen in profits. Conversely, the stock of manufacturing equipment-related design patents has a negative impact in Model [2], although its statistical significance remains at the $10 \%$ level. The flow of trademark rights also shows a positive correlation in Model [2], but it has no significant impact in Model [1]. However, this result is not robust.

The estimation results of the growth rate of sales shows a significant positive effect of the stock of manufacturing equipment design patents. The coefficient implies that each additional stock increases the sales growth rate from $1.0 \%$ to $1.7 \%$ (Table 4 ).

\subsection{IPR flows}

The estimation results of growth rate of sales indicate that the flow of food shapes and tableware design patents significantly and positively correlated with the dependent variable. However, the impact is not high (0.27 to $0.3 \%)$.

On the other hand, when growth of operating profits was set for the dependent variable, we could not have confirmed any statistically significant influence in any independent variables (Table 5). 
Table 4 Regression results of operating profits, growth of sales, and operating profits (IPRs' stocks)

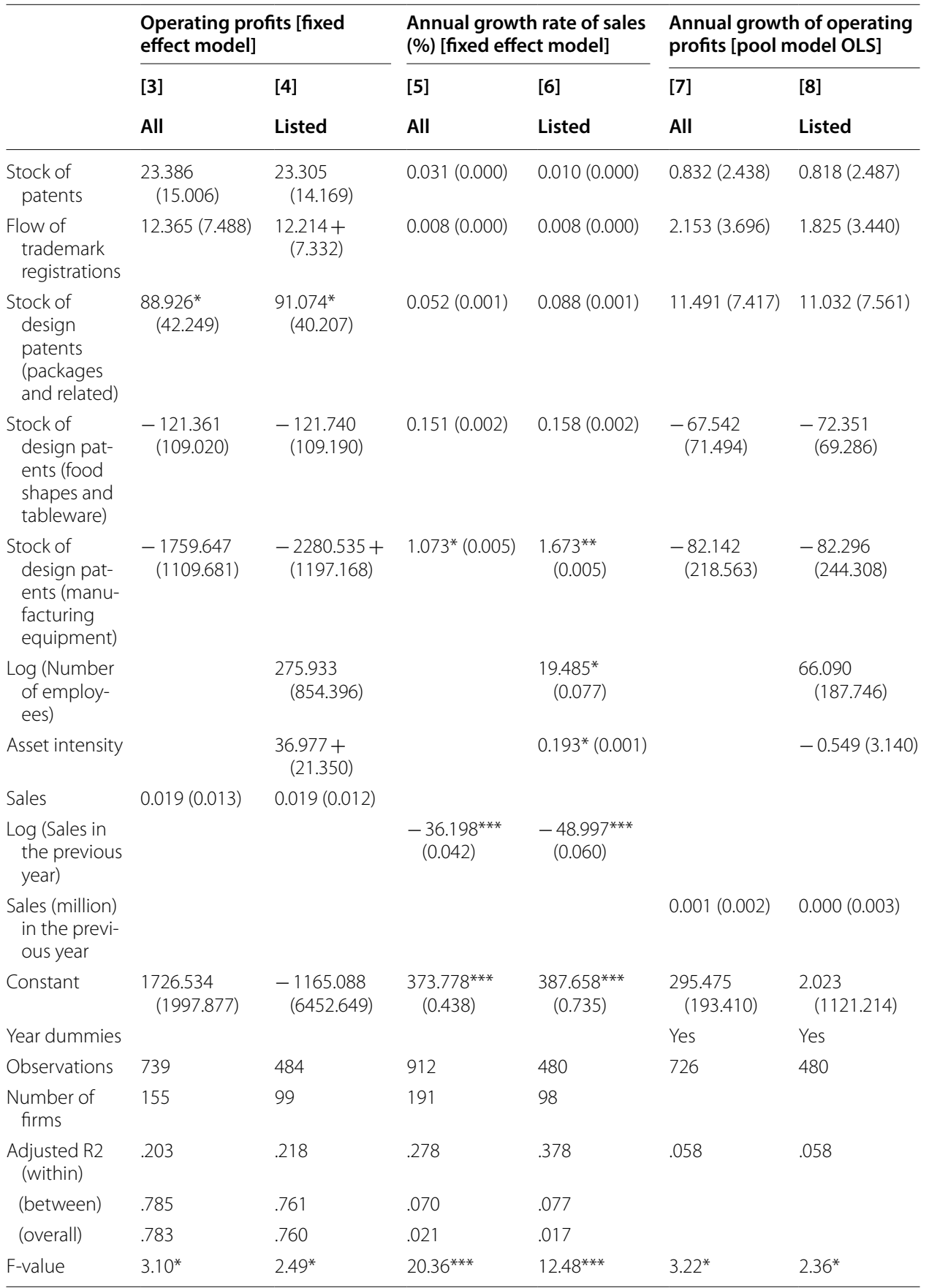

Cluster robust errors are in parentheses

${ }^{* * *} p<0.1 \%,{ }^{* *} p<1 \%,{ }^{*} p<5 \%,+p<10 \%$

\section{Discussion}

Design patents show several significant impacts. First, the stock of packages and related design patents brings high operating profits, but they do not always involve their growth. Consistent with the latter result, the flow of these designs also has no 
Table 5 Regression results of growth of sales and operational profits (IPR flows)

\begin{tabular}{|c|c|c|c|c|}
\hline & \multicolumn{2}{|c|}{$\begin{array}{l}\text { Annual growth rate of sales (\%) [fixed } \\
\text { effect model] }\end{array}$} & \multicolumn{2}{|c|}{$\begin{array}{l}\text { Annual growth of operating profits } \\
\text { [pool model OLS] }\end{array}$} \\
\hline & {$[1]$} & {$[2]$} & [1] & [2] \\
\hline & All & Listed & All & Listed \\
\hline $\begin{array}{l}\text { Flow of patens (previous } \\
3 \text { years) }\end{array}$ & $-0.019(0.000)$ & $-0.009(0.000)$ & $1.318(6.024)$ & $1.486(6.453)$ \\
\hline $\begin{array}{l}\text { Flow of trademark registra- } \\
\text { tions }\end{array}$ & $0.011(0.000)$ & $0.008(0.000)$ & $2.466(4.554)$ & $2.137(3.763)$ \\
\hline $\begin{array}{l}\text { Flow of design patents (pack- } \\
\text { ages and related) }\end{array}$ & $0.136(0.001)$ & $0.149(0.001)$ & $46.878(50.630)$ & $43.435(53.952)$ \\
\hline $\begin{array}{l}\text { Flow of design patents (food } \\
\text { shapes and tableware) }\end{array}$ & $0.303^{* *}(0.001)$ & $0.273^{* *}(0.001)$ & $64.024(121.682)$ & $58.551(116.731)$ \\
\hline $\begin{array}{l}\text { Flow of design patents } \\
\text { (manufacturing equipment) }\end{array}$ & $-0.129(0.004)$ & $-0.008(0.002)$ & $512.493(368.840)$ & $521.589(407.770)$ \\
\hline Log (Number of employees) & & $20.359 *(0.080)$ & & $49.427(238.357)$ \\
\hline Asset intensity & & $0.197(0.001)$ & & $-1.015(3.153)$ \\
\hline $\begin{array}{l}\text { Log (Sales in the previous } \\
\text { year) }\end{array}$ & $-36.404^{* * *}(0.042)$ & $-49.054^{* * *}(0.060)$ & & \\
\hline $\begin{array}{l}\text { Sales (million) in the previous } \\
\text { year }\end{array}$ & & & $0.000(0.002)$ & $0.000(0.002)$ \\
\hline Constant & $378.123^{* * *}(0.440)$ & $384.566^{* * *}(0.747)$ & $284.917(192.322)$ & $115.209(1436.037)$ \\
\hline Year dummies & & & Yes & Yes \\
\hline Observations & 912 & 480 & 726 & 480 \\
\hline Number of firms & 191 & 98 & & \\
\hline Adjusted R² (within) & .268 & .371 & .059 & .060 \\
\hline (between) & .064 & .073 & & \\
\hline (overall) & .019 & .017 & & \\
\hline F-value & $14.33^{* * *}$ & $11.18^{* * *}$ & $3.47^{* * *}$ & $2.80^{* * *}$ \\
\hline
\end{tabular}

Cluster robust errors or robust errors are in parentheses

*** $p<0.1 \%,{ }^{* *} p<1 \%,{ }^{*} p<5 \%,+p<10 \%$

significant effect. We can interpret this as premium pricing that helps realize stable, high revenue. IPIs generate a product's brand while increasing loyal consumers' willingness to pay. This interpretation is consistent with several marketing studies, which mentions that new package designs improve consumers' willingness to pay premium prices (Prendergast and Pitt 1996; Young 2004). Interestingly, although profits increase, sales are (on average) not significantly high. Our results imply that loyal customers do not buy more. More precisely, in some cases, maintaining the same communication channel may decrease sales since nonroyal customers do not focus on non-novelty packaged products. In addition, our results possibly reflect such a negative effect, which, in turn, can offset the effect of premium pricing. In short, these results support Hypothesis 2 and reject Hypothesis 1.

Second, the design patents of food shapes and tableware can accelerate the growth of sales and maintain a high level of sales. These results indicate the eye-catching effect of novel shapes on the purchasing decisions of products or tableware. However, this effect does not improve revenue. Since these designs are not the primary communication channel to consumers at the point of purchase, they may display their value at the point of consumption. Thus, it is difficult to determine whether the consumers perceive a higher willingness to pay. At least, it is possible to conclude that manufacturers have 
difficulty reflecting the attractiveness of the products(s) in the price. Also, our argument can be extended to the linkage with innovation activities. In regard to food shapes, the majority are outcomes of new product development.

Third, although the stock of manufacturing equipment-related design patents brings sales growth, it has an opposite effect on operating profits. This implies that the competitiveness in the manufacturing process can increase sales, but it can also decrease profits. Still, it may be considered as a reverse causality. Moreover, firms might have a tendency to collect numerous design patents in the manufacturing process to maintain their market share when they are about to lose their position. As a highly asset-intensified industry, process streamlining is a quick remedy for ailing firms as well as critical for large firms. Thus, the estimated coefficient may show a highly and substantially large negative impact.

Among these various design patents, only packages and related design patents can improve profits. This fact reveals that the exclusive use of marketing tools can generate stable rent. Moreover, package designs and primary communication channels at the point of purchase can drive firm performance. Our results indicate the importance of inimitable IPIs among other protected innovation outcomes. Therefore, Hypothesis 3 is supported.

The results of this analysis indicate that technological innovations have no significant impact on firm performance. These results are not consistent with the findings of Grashuis and Dary (2019), who investigated the food- and beverage-manufacturing industry in the US and found qualified patents increase firm value. This inconsistency seems to represent a difference of market structure between the US and Japan. As debated above, Japanese market has no dominant firms in which economics of scales have limited impact on financial performance, and thus, process innovations associate marginal effects. Furthermore, Japanese consumers relatively prefer organic foods (e.g., Sahota 2009) and technology-oriented product innovations are hard to be accepted. Considering that some Asian and European countries share these characteristics, our unexpected results probably illustrate the peculiarity of the US food industry. Indeed, our results also rationalize the low intensity of technology development in this industry (Garcia Martinez and Briz 2000). However, our patent-based analysis has a limitation. As Encaoua et al. (2006) argued, firms must pay a significant cost for applying and maintaining patents. If the return on technology development is insufficient, then some firms avoid applying for patents and keep technologies as secret knowhow. Our results should not be interpreted as negative evidence for technology development in the food and beverage industry.

The findings also show that trademark rights have limited and unstable effects on firm performance and that there is a significant positive (but non-robust) effect of trademark applications on operating profits. These results suggest that new product development does not always improve firm performance. Moreover, although Krasnikov et al. (2009) discovered a positive correlation between return of assets and trademark applications that evoke brands, we did not consider the characteristics of trademarks. The report published by the Japan Patent Office pointed out that some firms have registered multiple trademarks regardless of product development to maintain freedom of naming. Furthermore, in the Japanese food manufacturing industry, $60 \%$ of trademark registrations 
remained unused, which is a relatively high ratio (Japan Patent Office 2010b). These unused trademark rights can lead to additional unnecessary trademark applications to ensure the freedom of naming. This self-strengthened, unused trademark registration cycle in the food industry generates noise in the dataset. In this study, we used trademark right as a proxy variable for product innovation output, but there is a possibility that this assumption was erroneous. Combined with the findings from the estimations of effects of manufacturing equipment-related design patents, these results suggest that the major part of new product development activities does not always bring substantial benefits. This may be because new product introduction always comes with high advertising costs and some benefit-sharing (or rebates) with wholesalers in the highly competitive industry.

Simultaneously, the results do not reject any positive effects regarding the stocks of trademarks, which we did not observe. As Greenhalgh et al. (2011) discovered, there is a positive correlation between having at least one trademark right and the growth rate of sales. However, as the vast majority of the firms in our study had at least one trademark right, we did not investigate this effect.

\section{Conclusion}

\subsection{Academic contribution}

Overall, this study achieved three different academic contributions. First, the findings augmented the arguments in innovation strategies and revealed the superiority of the IPI in the food- and beverage-manufacturing industry. Previous literature has precisely and separately investigated the impact of different types of innovations and also did not consider the influences of the probability of imitations. This study, adopting IPRs as proxies of innovation activities, realized an integrated research approach and revealed an economic value of IPIs in the fiercely competitive and matured industries. In such industries, the primary interest is in process innovations such as manufacturing process improvements and supply chain optimizations. This study added another strategic factor to innovation studies in specific business environments.

Second, this research design expanded the method of using design patents in econometric research; that is, they need to be separated by their related innovation activities. Design patents, in contrast to patents or trademarks, contain three distinct innovation outcomes: (1) aesthetical product innovations; (2) IPIs; and (3) incremental process innovations. These mixtures (we assume) offset some of the significant effects of design patents in previous studies. However, limited studies have conducted econometric analyses regarding the effect of having design patents, especially in the food industry. Outcomes of separate innovation activities emerge in different products, e.g., IPIs are in package designs, whereas process innovations occur in manufacturing tools. This situation, which fits our research design, helps identify the different effects of design patents, especially under the outcomes of different innovation activities. Our methodological contribution will help expand the methods of empirical research using design patents.

Third, this finding is an important contribution to academic research on IPRs. As argued above, previous studies have discovered an unstable effect of design patents on firm performance. This study detects a significant positive effect of stock of design patents by classifying them into communication-related designs and manufacturing-related 
articles. Some part of design patents creates the competitive advantage on average. It seems that a number of design patents in all fields are a noisy index as design patents cover various types of innovation results, such as technological achievements, aesthetical novel articles, and a part of graphic design works. However, once we limited them in the specific innovation activities, this measurement well captures certain innovations.

\subsection{Practical implications}

One of the crucial strategic decisions is whether firms should make significant investments in new product development or branding activities in the food and beverage manufacturing industries. Our investigation on Japanese firm performance between 2009 and 2013 found several proxies of new product developments, such as trademark applications and design patents registrations of food shapes, which showed extremely limited positive effects. Only additional new design patents' registration of food shapes improved sales at $0.3 \%$, whereas no statistically significant effect on profits was found. However, the stock of package design-related rights, a proxy of existing product branding, was shown to continuously improve profits. In fact, each additional stock generated 80 million Japanese yen (approximately 0.7 million USD) in profits. This high and stable impact apparently illustrates the advantage of branding activities through communication channels such as package designs and advertisement equipment.

The findings show that branding by the communication channel is not an omnipotent strategic option and it does not always improve sales. In some instances, it decreases sales. New registrations of package designs have no significant impact on the growth of sales, and we did not obtain any support for the argument of Schoormans and Robben (1997), which emphasized the positive effect of new package designs on the willingness to pay. In contrast, new food shapes or tableware, of which consumers cannot directly observe at the time of purchase, seems to have a positive impact on the willingness to buy. Although our empirical test on firm performance did not identify any consumer behavior, these findings suggest that future research continues to focus on consumer behaviors in response to novel package designs and the branding of existing products.

\subsection{Limitations and future studies}

Our empirical study revealed several findings that have been left uninvestigated, due to the scarcity of measurable data. However, we contributed to such insufficiency by utilizing design patent data. Of course, our dataset also contained several limitations. Thus, the readers of this study should carefully interpret the following issues. First, IPRs are not the direct outcome of innovation activities. One of the most important mediators is the propensity for applying IPRs. However, some firms apply for a very limited number of IPRs. For example, SMEs show a low propensity, due to their resource limitations. Considering this limitation, we only observed publicly listed firms and influential nonlisted firms. In other words, SMEs were out of the range of our implications. Second, our research design benefited from the structure of the Japanese food and beverage industry. More specifically, most of the firms conducted domestic business and shared similar supply chains; that is, they purchased raw materials from the agricultural cooperative association and food additives' manufacturers and distributed the processed foods/beverages to wholesalers. This homogeneity justified our fixed model estimation. 
Conversely, some SMEs changed their business model to a direct online sales model. Therefore, our findings are not applicable to the management of SMEs.

Finally, this study raises several future research questions. First, our firm-level analysis suggested a conditional positive effect of new food shapes. It is interesting that these elements can positively improve sales, even though consumers do not directly realize the novel shapes at the point of purchase and there might be some interactions with package designs or advertisement. Therefore, this question is open to future product-level analyses. Second, we did not fully investigate any interactions among distinct innovation activities, and there are no theoretical claims regarding the trade-offs between product innovations, IPIs, and process innovations. Although our preliminary analysis (not reported here) on these interactions did not find any robust evidence, further refinement of the dataset, such as adding other data sources, can lead to some important implications. Third, branding itself may self-aggrandize the difficulty in imitations from competitors. Except for unscrupulous firms, no firm intends to copy well-known brands. The superiority of holding a package design may be a result of the strong protection.

Acknowledgements

Not applicable.

\section{Authors' contributions}

TYK and TM analyzed characteristic of Japanese food industry, and examined the effect of intellectual properties such as patents, trademarks, and design patents. DK was a major contributor in writing the manuscript. All authors read and approved the final manuscript.

Funding

This work was supported by JSPS Grants-in-Aid for Scientific Research (KAKENHI) Grant Number 16 K03894.

Availability of data and materials

Not applicable.

Competing interests

The authors declare that they have no competing interests.

\section{Author details}

${ }^{1}$ Institute of Innovation Research, Hitotsubashi University, 2-1, Naka, Kunitachi, Tokyo, Japan. ${ }^{2}$ Department of International Biobusiness Studies, Tokyo University of Agriculture, 1-1-1, Sakuragaoka, Setagaya, Tokyo, Japan. ${ }^{3}$ School of Economics, Kanazawa University, Kakuma-machi, Kanazawa, Japan.

Received: 30 October 2019 Revised: 13 January 2020 Accepted: 11 April 2020

Published online: 20 April 2020

\section{References}

Aguilera JM (2006) Seligman lecture 2005 food product engineering: building the right structures. J Sci Food Agric 86(8):1147-1155

Ailawadi KL, Lehmann DR, Neslin SA (2003) Revenue premium as an outcome measure of brand equity. J Market 67(4):1-17

Alfranca O, Rama R, von Tunzelmann N (2002) A patent analysis of global food and beverage firms: the persistence of innovation. Agribusiness 18(3):349-368

Aoki Y, Odagiri H (2008) Economic impact of intangible asset on firm's market value. In: In Japan Patent Office (ed) Survey on industrial property right applications in Japan. Tokyo, Japan Patent Office, pp 36-60

Archibugi D, Cesaratto S, Sirilli G (1991) Sources of innovative activities and industrial organization in Italy. Res Policy 20(4):299-313

Avermaete T, Viaene J, Morgan EJ, Pitts E, Crawford N, Mahon D (2004) Determinants of product and process innovation in small food manufacturing firms. Trends Food Sci Technol 15(10):474-483

Bascavusoglu-Moreau E, Tether B (2011) Design economics chapter two: registered designs \& business performanceexploring the link (SSRN Scholarly Paper No. ID 2707111). Social Science Research Network, Rochester

Batterink M, Wubben E, Omta S (2006) Factors related to innovative output in the Dutch agrifood industry. J Chain Netw Sci 6(1):31-44

Beckeman M, Skjöldebrand C (2007) Clusters/networks promote food innovations. J Food Eng 79(4):1418-1425

Bhaskaran S (2006) Incremental innovation and business performance: small and medium-size food enterprises in a concentrated industry environment. J Small Bus Manage 44(1):64-80 
Bigliardi B, Galati F (2013) Innovation trends in the food industry: the case of functional foods. Trends Food Sci Technol 31(2):118-129

Capitanio F, Coppola A, Pascucci S (2010) Product and process innovation in the Italian food industry. Agribusiness 4(26):503-518

Christensen JL, Rama R, Von Tunzelmann N (1996) Study on innovation in the European food products and beverages industry. European innovation monitoring system. European Commission: EIMS publication, Luxembourg

Comanor WS, Scherer FM (1969) Patent statistics as a measure of technical change. J Polit Econ 77(3):392-398

Confédération des Industries Agro-Alimentaires de I'UE (CIAA) (2008) Review of key competitiveness indicators for the European food industry. CIAA, Brussels

Dernis H, Dosso M, Hervas F, Millot V, Squicciarini M, Vezzani A (2015) World Corporate Top R\&D Investors: Innovation and IP bundles. Joint Research Centre, Seville

Doyle P (2000) Valuing marketing's contribution. Eur Manage J 18(3):233-245

Encaoua D, Guellec D, Martínez C (2006) Patent systems for encouraging innovation: lessons from economic analysis. Res Policy 35(9):1423-1440

Ernst $\mathrm{H}$ (2001) Patent applications and subsequent changes of performance: evidence from time-series cross-section analyses on the firm level. Res Policy 30(1):143-157

Fernández-Barcala M, González-Díaz M (2006) Brand equity in the European fruit and vegetable sector: a transaction cost approach. Int J Res Mark 23(1):31-44

Filitz R, Henkel J, Tether BS (2015) Protecting aesthetic innovations? An exploration of the use of registered community designs. Res Policy 44(6):1192-1206

Fleming L, Sorenson O (2001) Technology as a complex adaptive system: evidence from patent data. Res Policy 30(7):1019-1039

Garber LL, Burke RR, Jones JM (2000) The role of package color in consumer purchase consideration and choice. Marketing Science Institute, Cambridge

Garcia Martinez M, Briz J (2000) Innovation in the Spanish food \& drink industry. Int Food Agribus Manage Rev 3(2):155-176

Grashuis J (2019) The impact of brand equity on the financial performance of marketing cooperatives. Agribusiness 35(2):234-248

Grashuis J, Dary S (2017) An empirical investigation of patent and trademark ownership propensity and intensity in the US food and drink industry. Int Food Agribus Manage Rev 20(5):747-764

Grashuis J, Dary S (2019) Patented innovation and firm value in the U.S. food and drink industry: the economic importance of high-quality product innovation. J Agric Food Ind Org 17(2):20170002

Greenhalgh, C., \& Rogers, M. (2007). Trade marks and performance in UK firms: Evidence of Schumpeterian competition through innovation. University of Oxford Department of Economics Discussion Paper Series No. 300

Greenhalgh C, Rogers M, Schautschick P, Sena V (2011) Trade mark incentives. United Kingdom Intellectual Property Office, London

Grunert KG, Jeppesen LF, Jespersen KR, Sonne A-M, Hansen K, Trondsen T, Young JA (2005) Market orientation of value chains. Eur J Mark 39(5/6):428-455

Gunday G, Ulusoy G, Kilic K, Alpkan L (2011) Effects of innovation types on firm performance. Int J Prod Econ 133(2):662-676

Hsu FJ, Chen MY, Chen YC, Wang WC (2013) An empirical study on the relationship between R\&D and financial performance. J Appl Finance Bank 3(5):107-119

Huang R, Sarigöllü E (2014) Assessment of brand equity measures. Int J Market Res 56(6):783-806

Hullova D, Simms CD, Trott P, Laczko P (2019) Critical capabilities for effective management of complementarity between product and process innovation: cases from the food and drink industry. Res Policy 48(1):339-354

Japan Patent Office (2007) Annual report on design patent applications (2006FY). Survey on industrial design development, management, protection and design patent strategies. Japan Patent Office, Tokyo (In Japanese)

Japan Patent Office (2010a) Annual report on design patent applications (2009FY). In: Jeni M (ed) Survey on design patent strategies for the protection of promotional articles. Japan Patent Office, Tokyo (In Japanese)

Japan Patent Office (2010b) Annual report on trademark applications (2009FY). In: Jeni M (ed) Survey on strategies on trademark applications and management, and current status on unused trademarks. Japan Patent Office, Tokyo (In Japanese)

Japan Patent Office (2011) Japan's product design strategy and examples of intellectual property rights. Japan Patent Office, Tokyo

Japan Patent office (2017) Research on design patents application trends-macro survey. Japan Patent office, Tokyo

Kathuria LM, Gill P (2013) Purchase of branded commodity food products: empirical evidence from India. Br Food J 115(9):1255-1280

Keller KL (2003) Strategic brand management: building, measuring, and managing brand equity. Prentice Hall, New Jersey

Keller KL, Lehmann DR (2006) Brands and branding: research findings and future priorities. Market Sci 25(6):740-759

Knowles J (2003) Value-based brand measurement and management. Interact Market 5(1):40-50

Krasnikov A, Mishra S, Orozco D (2009) Evaluating the financial impact of branding using trademarks: a framework and empirical evidence. J Market 73(6):154-166

Mendonça S, Pereira TS, Godinho MM (2004) Trademarks as an indicator of innovation and industrial change. Res Policy 33(9):1385-1404

Menrad K (2004) Innovations in the food industry in Germany. Res Policy 33(6-7):845-878

Nakamura K, Matsumoto Y (2009) Explorative study on economic impact of design patent development, application and holding to firm value. In: Japan Patent Office (ed) Survey on industrial property right applications in Japan. Japan Patent Office, Tokyo (in Japanese)

Narayan G (2012) Brand valuation: a strategic tool for business (SSRN Scholarly Paper No. ID 2180752). Social Science Research Network, Rochester 
Omta SWF, Folstar P (2005) Integration of innovation in the corporate strategy of agri-food companies. In: Jongen WMH, Meulenberg MTG (eds) Innovation in Agri-Food systems; product quality and consumer acceptance. Wageningen Academic Publishers, Wageningen, pp 223-246

Prajogo DI (2016) The strategic fit between innovation strategies and business environment in delivering business performance. Int J Prod Econ 171:241-249

Prendergast G, Pitt L (1996) Packaging, marketing, logistics and the environment: are there trade-offs? Int J Phys Distrib Log Manage 26(6):60-72

Rama R, von Tunzelmann N (2008) Empirical studies of innovation in the food and beverage industry. In: Rama R (ed) Handbook of innovation in the food and drink industry. Haworth Press, New York, pp 13-49

Sahota A (2009) The global market for organic food \& drink. In: Willer H, Yussefi-Menzler M, Sorensen N (eds) The world of organic agriculture: Statistics and emerging trends 2008. International Federation of Organic Agriculture Movements, Bonn, pp 59-64

Sandner PG, Block J (2011) The market value of R\&D, patents, and trademarks. Res Policy 40(7):969-985

Schautschick P, Greenhalgh C (2016) Empirical studies of trade marks-the existing economic literature. Econ Innov New Technol 25(4):358-390

Scherer FM (1965) Corporate inventive output, profits, and growth. J Polit Econ 73(3):290-297

Schoormans JP, Robben HS (1997) The effect of new package design on product attention, categorization and evaluation. J Econ Psychol 18(2-3):271-287

Silayoi P, Speece M (2007) The importance of packaging attributes: a conjoint analysis approach. Eur J Mark 41(11/12):1495-1517

Traill W, Meulenberg M (2001) Innovation in the food industry. Agribusiness 18(1):1-21

Triguero Á, Córcoles D, Cuerva MC (2013) Differences in innovation between food and manufacturing firms: an analysis of persistence. Agribusiness 29(3):273-292

Trott P, Simms C (2017) An examination of product innovation in low- and medium-technology industries: cases from the UK packaged food sector. Res Policy 46(3):605-623

Xin JY, Yeung ACL, Cheng TCE (2010) First to market: is technological innovation in new product development profitable in health care industries? Int J Prod Econ 127(1):129-135

Yamauchi I, Furusawa Y, Edamur K, Yoneyama S (2012) Know-how management and innovation performance. NISTEP Discussion Paper, 84. [in Japanese]

Yoshioka-Kobayashi T, Fujimoto T, Akiike A (2018) The validity of industrial design registrations and design patents as a measurement of "good" product design: a comparative empirical analysis. World Patent Inf 53:14-23

Young S (2004) Winning at retail: research insights to improve the packaging of children's products. Young Consum $5(1): 17-22$

\section{Publisher's Note}

Springer Nature remains neutral with regard to jurisdictional claims in published maps and institutional affiliations.

\section{Submit your manuscript to a SpringerOpen ${ }^{\circ}$ journal and benefit from:}

- Convenient online submission

- Rigorous peer review

- Open access: articles freely available online

- High visibility within the field

Retaining the copyright to your article

Submit your next manuscript at $\boldsymbol{\nabla}$ springeropen.com 